\title{
Understanding Why People Change Their Technology Use in Protests: User Study on Ebonyi State Mobile Telecommunication Subscribers Experiences
}

\author{
Nwani Henry Ogbu, Ignatius Nwoyibe Ogbaga \\ Department of Computer Science, Ebonyi State University, Abakaliki, Nigeria \\ Email: address ogbu.henry@ebsu.edu.ng
}

How to cite this paper: Ogbu, N.H. and Ogbaga, I.N. (2021) Understanding Why People Change Their Technology Use in Protests: User Study on Ebonyi State Mobile Telecommunication Subscribers Experiences. Int. J. Communications, Network and System Sciences, 14, 119-133.

https://doi.org/10.4236/ijcns.2021.148008

Received: July 2, 2021

Accepted: August 28, 2021

Published: August 31, 2021

Copyright $\odot 2021$ by author(s) and Scientific Research Publishing Inc. This work is licensed under the Creative Commons Attribution International License (CC BY 4.0).

http://creativecommons.org/licenses/by/4.0/

\begin{abstract}
The rise in consumers complains against their service/tech providers has empowered government of various nations to set up Consumer Complaint Commissions. Some corporate organizations who wish to handle the complaints of their customers usually set up an in-house/internal customer care centres, a platform through which they attend to their customers' needs. This research therefore is interested in exploring the reasons for user-protests among the mobile telecommunication subscribers in Ebonyi State, Nigeria against their network service providers. To arrive at this, we designed a research questionnaire to capture the experiences of the subscribers of the 4 major mobile telecommunication network service provider companies operating in the state. The participants were recruited through physical administration of research instrument and social media such as facebook, whatsapp and email platforms with a total of 72 participants feedbacks received. The users responses on the various issues raised on our questionnaire were thematically analyzed and represented using adequate data presentation tools. Our results proved that there are growing numbers of disgruntled customers among subscribers of the various network providers. From our survey, we gathered that $81.90 \%$ of the respondents have engaged in protest use at one point or the other against their service providers with MTN network topping the list with $36.50 \%$, followed by GLO network 27\%, Airtel network $23.80 \%$ and 9 Mobile $12.70 \%$. Finally, we proposed a design prototype named "Komplain" that will serve as rallying system for the protest users to use and prosecute their actions. The system can also recommend actions which the protesters may undertake.
\end{abstract}




\section{Keywords}

User Protests, Disgruntled Users, Technology Non-Use, Protest Non-Use, MTN, NFR, 9 Mobile, Airtel

\section{Introduction}

Gradual changes in quality of companies products/services value over time usually lead to customer dissatisfactions, which if left promptly unchecked usually culminates into consumers/users protest against the services/products providers.

Therefore, protests against tech-service provider companies can take various dimensions whenever it occurs. The customers protesting may decide to stop or change the product/service demands from their companies. These reactions have continued to attract public attention. Instances abound, such as users boycotts against Facebook in order to protest against its illicit data harvesting and spread of misinformation [1] [2] customers boycotts against Uber company in protest against its insensitive behavior surrounding taxi strike and sexual harassment involving their staff [3] and boycotts against Amazon in protest against their un-favourable working conditions and anti-tax lobbying [4].

However, some scholars have taken it upon themselves to ascertain what really spurs people up to embark on protests against technology companies [5] [6] [7] [8]. For instance, Vincent et al. recently explored the concepts of "data strikes" and "data boycotts" against large-scale machine learning systems [8]. The result of their findings motivated Posner and Weyl to propose the formation of "data unions" [7]. Generally, human-computer interactions (HCI) researchers such as [9] [10] [11] [12] have all suggested for comprehensive study on non-use behaviours in order to obtain accurate understanding of the factors that triggers users protests against their service providers.

Undoubtedly, Nigeria has one the fastest growing telecommunications markets in Africa, considering the size of her subscribers-base. Setback to this remarkable growth has been the persistent consumer dissatisfactions with the quality of services rendered to their network subscribers by the service providers. One of the major telecommunication companies in Nigeria was fined a total of three million two hundred and fifty thousand $(\$ 3,250,000)$ dollars by the Nigeria Government for poor quality services delivery in 2012. These Quality of Service (QoS) problems have been attributed to inefficiencies in the operational activities of the operators, who have in turn blamed it on peculiar features of the $\mathrm{Ni}$ gerian environment in which they operate [13]. For instance, in some areas, there will be abundant network service while in some parts, there will be none while most of the places that have network service usually experience high network downtime than uptime. Hence, this research is to ascertain the reactions of teeming subscribers of these telecom companies with Ebonyi state subscribers in focus. 
From the result of our survey, this paper presents a descriptive understanding of those that we are referring to as protest/dissatisfied users. They are current or past subscribers of these network providers' services who decided to change (protest use) or stop (protest non-use) their original network service providers due to unfavorable actions of their service providers. Our survey sampled adult mobile phone users in Ebonyi State Nigeria. The explorative survey for this research was conducted from March-June, 2020 with 72 respondents $(\mathrm{N}=72)$. In particular, we examined the factors that spur subscribers into user protest among the customers of four major telecommunication companies in Nigeria (MTN, GLO, Airtel and 9 Mobile), operating in Ebonyi State and the palpable way forward out of this menace.

Our results indicated that large share of mobile phone network subscribers in Ebonyi State Nigeria are protest users. $83.3 \%$ of our respondents reported to have engaged in user protest with at least one network provider/operator. This number is substantial enough to prove that these network providers are not living up to the expectations of their customers, hence the increased protests. It is only $16.70 \%$ of the subscribers indicated that they have never engaged in user protest. The statistics of the protesters among the four major network service providers in the state are distributed thus: MTN network 36.5\%, GLO network 27\%, Airtel Network 23.80\% and 9 Mobile $12.70 \%$.

\section{Related Works}

This section shall specifically consider major literatures that bothered specifically on technology non-use and protests against technology companies.

\subsection{Protest Users and Technology Non-Use}

This study was largely influenced by the combined literatures on protest non-use in science and technology studies (STS) and Human-Computer Interactions (HCI) as aptly captured in the works of [10] [11] [12] [14] [15] [16]. These researchers maintained that irrespective of the prevailing perspectives in HCI, technology non-use could be considered a productive behaviour. In 2003, Wyatt advised scholars to always "see non-users and former users as relevant social group who might influence the shape of the world" [12]. Similarly, Satchell and Dourish called on HCI researchers to also consider non-users, and went on to dismiss the notion that non-use is an "absence" or "negative space" [11]. They maintained that if a user abandons product " $A$ " there must be an alternative product " $\mathrm{B}$ " which he will rely on and noted that non-use is not as absolute as the term implied

Accordingly, a recent literature contribution to technology non-use made the terms "user" and "non-use" complex by arguing that non-use should be treated as a ceaselessly bargaining practice [17] [18] which is not made up of binary distinction between users and non-users [9] [17] [19]. However, [9] [14] observed that activities surrounding technology non-use and use involves various beha- 
viours such as considering deactivation of an existing account and the subsequent deactivation of the said account, taking a break from a platform, creation of fake accounts, and many other fed-up behaviors from the users towards their network service providers.

We considered the complexity emphasized by [9] by taking into account those subscribers who still maintained their network service providers but are protesting by lowering their level of patronage to their service provider and the subscribers who have changed their service providers entirely out of protest. We use the term "protest non-use" when we are specifically referring to subscribers who reported total abandonment of their previous network service providers being their NFR while "protest users" are all subscribers who are protesting but still maintained their network service providers but out of protest may have lowered their level of commitment to their operators

\subsection{Users Protests against Tech Companies: Boycotts \& Buycutts}

Overtime, there have been several consumer protests against technology service companies, such as Uber, Facebook and Amazon, [1] [2] [3] [4] which can be compared to traditional consumer boycotts: a group of people withholding their commitment with their service providers in an attempt to compel them to change some of their obnoxious service policies towards them. Based on the foregoing, the large body of research on customers boycotts as contained the works of these renowned authors [20] [21] [22] serves as a veritable tool in providing us with sufficient insight during our study.

In the work of [23], it was enumerated how $28 \%$ of American consumers participated in "political consumption", which means either boycotting or "buycotting" (i.e. deliberately purchasing products to support a company). It was also observed that the number of protesters is even higher among some European countries, such as Sweden and Switzerland, where about 35\% of people have all engaged in consumer boycotts while around 58\% engaged in "buycotts" as noted in [24]. Interestingly, [13] pointed out that the outcomes of historical boycotts showed that they are not only prevalent but have also impacted negatively on both economy of the targeted companies and the society at large. For instance, the customers boycott against Uber in 2017 triggered a lot of sympathetic participation from the public in general which later compelled the company to tender public apology in order to quell the tension and as well reversed its obnoxious policy that triggered the protest.

Protesters approach in technology domain takes varying dimensions in accordance with the various sources through the company generates its revenue. For instance, advertisement is a primary source of revenue for some major tech companies such as Google and Facebook [25], whereas other companies sell products and services directly to consumers in order to generate their own revenues. Thus, protesting behaviors in tech domains include avoiding visits to the disgruntled website such as google.com, facebook.com, wiki.com, etc., refusing to purchase goods or services from the company such as konga.com, jumia.com, 
Uber and Amazon.com, or deactivation of ad-revenue generating platform [6]. In addition to the already mentioned protesters attitudes geared towards reducing the service providers' ad revenue, the consumers could also embark on "data strike" by withholding their "data labour". The data labour is generated when users provide inputs as they continue to access their service provider's websites or portal. These inputs could come in the form of cookies or user responses but when they abstain from accessing the platform; their data labour is apparently withheld. It is therefore noteworthy that users also posses' data labour power as mentioned in the works of [7] [8].

This study is however motivated by recent increase in "boycott-assistive technologies" [5] employing customers Buycott [26] and Out-of-Site techniques which is usually aimed at facilitating online and offline boycotts activities. This technology highlights the collective nature of boycotts and suggests to the participants the recommended actions to take at any point in time and the expected outcome of every action.

\section{Research Method}

In this report, we present our findings from our web-based survey conducted in the first quarters of 2020. The research survey was designed to ascertain in details, the rate of protest users among Nigeria mobile network service provider companies. We also sought to know the reasons behind their protests (protest-use and non-use) and the kind of techniques they employ in protesting. We employed thorough-spread sampling technique through a third party survey administration to respondents, as it is common in large-scale studies that have examined technology non-use e.g. [9] [14] [27].

\subsection{Research Survey Design and Participants Recruitment}

Our survey questions were designed with an intention of tailoring the questions to reflect the experiences of our target audience. Respondents' recruitment was done through physical contacts, emails and social media platforms such as facebook and whatsapp. We had 72 respondents who diligently completed our five (5) minutes research survey questions. The survey questions were categorized into free response and fixed-response questions. The fixed-responses questions were targeted at ascertaining the respondents' level of knowledge regarding technology users' protest, predominant gender of the protesters, choice of network and reasons behind users' protests, while the free-response questions are open-ended.

The result from our survey indicated that $82 \%$ of the respondents have engaged in protest against their network service providers. The answers to the motivations behind their protest were provided by the respondents in the free-response questions. Their motivations were summarized in following themes: poor service, high tariffs on calls \& internets, unnecessary charges, network issues, high cost of purchasing data bundle, high charges on internet services, and high 
charges on calls. While others attributed their reasons on no free services by their network service, because they have found a better network service provider, etc.

We also went further to ascertain their experiences with their present companies, whether it is better or not. Only $53 \%$ of the respondents are happy with their present network service provider while 11\% affirmed negative and 35\% could not really differentiate between their experiences with the former and present network service providers. We also found out that some answers to free-response questions are invalid so we could not classify them into any response group. Among the total number of respondents, only $67 \%$ of them are familiar with the term "protest user" while the remaining 33\% are not even aware of what they are doing despite their consistent engagement in the act.

\subsection{Respondents Demography}

Figure 1 below presents the demographic data we harvested from our research survey. All the demographic questions were made compulsory to all the respondents. The result obtained shows that our survey questions are reasonably distributed across a number of demographic factors with a slight representation of middle-high-income population. The reason for the high respondents of middle-high-income respondents is because they represent the majority of people who have the high-end devices that could access our online survey. Our survey also indicated that the age brackets of our respondents ranges from 18 - 30 years which represents $57 \%$ and followed by age brackets of $31-40$ years which also represent $24 \%$ responses.

The respondents were categorically classified into two folds; male and female with male respondents higher than the female respondents with majority of them highly educated.

However, it is good to note that some of our findings were not reported in percentages. Only results relating to motivations are reported in percentages. Some respondents reported more than one motivation behind their protests against their previous network service providers. So, one respondent can have multiple instances spread across multiple network service providers in the country. An example is a case where a subscriber is protesting against MTN because of high tariffs on calls and is also protesting against GLO because of slow internet browsing network. In our results, we report both the number of instances for each network service provider, and instances summed across network companies.

\section{Our Research Results}

Figure 2 below illustrates the results from our survey. The format we employed in our result presentation is percentage format, with special interest in those are protest users and their respective network service providers. We also unpacked the motivations and setbacks associated with protest users. 


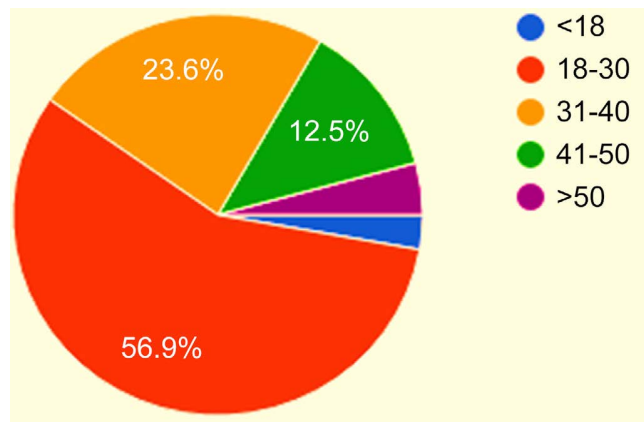

Figure 1. The pie chart representing the age brackets of our respondents in the survey.

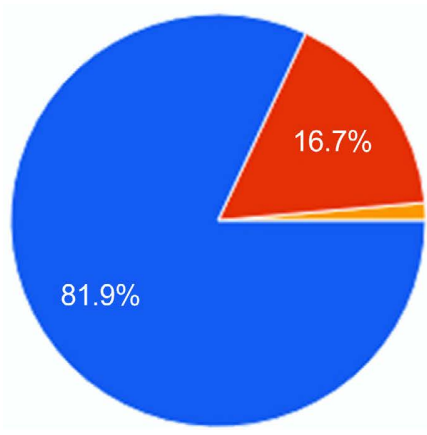

\author{
Yes \\ No \\ Based on the given definition, yes
}

Figure 2. The figure illustrating those who have engaged in protest use against their service provider.

\title{
4.1. Prevalence of Protest Users in Ebonyi State of Nigeria
}

The high-level result from our survey shows that the generality of those who have embarked on users protests are $82 \%$ - both those who were aware of what they were doing and those who were not. Large chunks of the protesters are not aware of what user protest is all about even when they have consistently engaged in it. We mentioned in $\mathbf{3 . 1}$ that it is only $67 \%$ of our respondents knew what protest use is all about, $33 \%$ of them were not familiar with the term prior to our research.

Figure 2 above goes on to confirm the total number of our respondents who have engaged in user protest against their network service providers. It is only $16.7 \%$ percent of the user that have maintained their network of first registration (NFR).

\subsection{Rate of Protest Users against Each of the Telecom Companies}

Our survey as can be seen in Figure 3 below tried to identify the number of protest users against the four network provider companies in Nigeria in order to determine which of the company has the highest number of protesters. This question is also insightful because it shall help us in our decision about which company delivers the best or worst quality of service to their customers.

The responses we obtained shows that approximately $37 \%$ of MTN subscribers have engaged in protest against the company, followed by GLO with $27 \%$ of its subscribers and 9 mobile with $13 \%$ of its subscribers. 


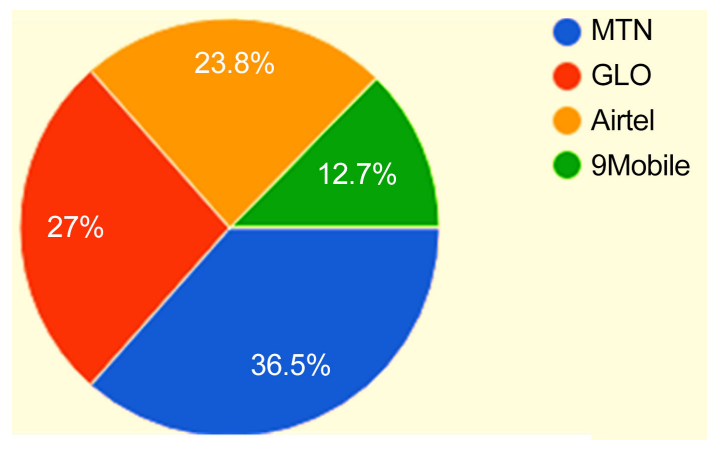

Figure 3. Protest users against the four major network service providers.

\subsection{Motivations behind User Protests}

From our survey, we were able to understand that the subscribers embarked on protests for different reasons. For instance, with their knowledge of internet access via cable television network [28], they never expected less from their mobile network service providers. So, they got disappointed when their present network service providers could not meet up to their expectations based on their previous experiences.

Our survey revealed that following are the major reasons behind the users protest:

1) Poor network service delivery;

2) High tariffs on both call and data services;

3) Unnecessary charges for unsolicited services such as caller tunes;

4) Unreliable networks service, i.e. high network downtime;

5) High cost of purchasing data bundles;

6) High tariffs on data services;

7) High charges on calls made;

8) Poor internet services;

9) Too much unsolicited messages from their network providers;

10) Change of location because their NFR service is not available in their new location;

11) They found a better network service provider;

12) There is no free service offered by their network providers for instance, MTN offers free data service for social media and banking application services.

These reasons are summarized in Table 1 below.

Table 1. Factors that motivate user protest across the network service providers.

\begin{tabular}{|c|c|c|c|c|c|c|c|c|c|}
\hline Factors & $\begin{array}{c}\text { Poor } \\
\text { service }\end{array}$ & $\begin{array}{c}\text { High tariffs } \\
\text { both call \& } \\
\text { internet }\end{array}$ & $\begin{array}{c}\text { Unnecessary } \\
\text { charges }\end{array}$ & $\begin{array}{l}\text { Network } \\
\text { Issues }\end{array}$ & $\begin{array}{l}\text { High cost } \\
\text { of Data } \\
\text { bundle }\end{array}$ & $\begin{array}{c}\text { High } \\
\text { charges for } \\
\text { internet }\end{array}$ & $\begin{array}{l}\text { high } \\
\text { charges } \\
\text { for call }\end{array}$ & $\begin{array}{c}\text { poor } \\
\text { internet } \\
\text { service }\end{array}$ & Others \\
\hline Total & 8 & 8 & 3 & 19 & 6 & 10 & 3 & 1 & 10 \\
\hline$\%$ & $11.10 \%$ & $11.10 \%$ & $4.20 \%$ & $26.40 \%$ & $8.30 \%$ & $13.90 \%$ & $4.20 \%$ & $1.40 \%$ & $13.90 \%$ \\
\hline
\end{tabular}


Table 1 indicates that the majority of the protest is caused by network issues with $24.40 \%$, followed by high for internet services and other issues representing $14 \%$ on approximation while poor service and high tariffs on calls and internet closely followed with $11 \%$ of the protesters

\subsection{Network Service Providers and Various Subscriber Bases}

Our study revealed that among the four major network service providers in Nigeria, MTN network has the highest number of subscriber while 9 mobile has the least number of subscriber base. This may be as a result of series of acquisition and re-acquisition of the company that made them loose most of their customers. 74\% of our respondents are MTN subscribers while 9 mobile has $7 \%$ of the subscribers. Figure 4 below illustrated the better picture.

The bar chart also indicated that GLO and Airtel are closely following each other with $36 \%$ and $39 \%$ percents respectively.

Our survey also indicated that $63 \%$ of the respondents believed that MTN network is the best, closely followed by Airtel with 22\%. GLO and 9 mobile fell between $8 \%$ and $2 \%$, indicating that the reliability of their service is very low. Upon the rating of some of the network providers, some people still believe that none of them is good and so, it is better to remain and tolerate any of the network providers they have registered with.

\subsection{Users Comfortability with Their Network Service Providers}

Our study also sought to determine how many of the subscribers are happy/comfortable with their networks service providers. Considering the onerous challenges facing the network service providers in the competitive market. From the users experiences, $53 \%$ of the subscribers are happy with their network service providers while $11 \%$ are not and $35 \%$ are not really sure. They are neutral in the matter. Figure 5 below illustrates the user experience better.

\section{Discussions}

Generally, our study result suggests that protest users have formed themselves into a formidable force in the socio-technical domain. Even though our survey did not cover large number of respondents, we observed that 59 respondents, representing $82 \%$ of our respondents are protest users. These results, along with other detailed findings about the motivations, challenges and subscriber experiences, have serious implications for varieties of stakeholders, including researchers in social computing and other areas of computing technology. These implications are explicitly discussed in the following subsections provided below.

\subsection{Technologies Support for Protest Users}

The social computing literatures and wider computing community have suddenly increased their interest in developing technologies to support protest users [5] [26] and protective optimization technologies [29]. From our study, it was observed that most of the subscribers are disgruntled with their network service 


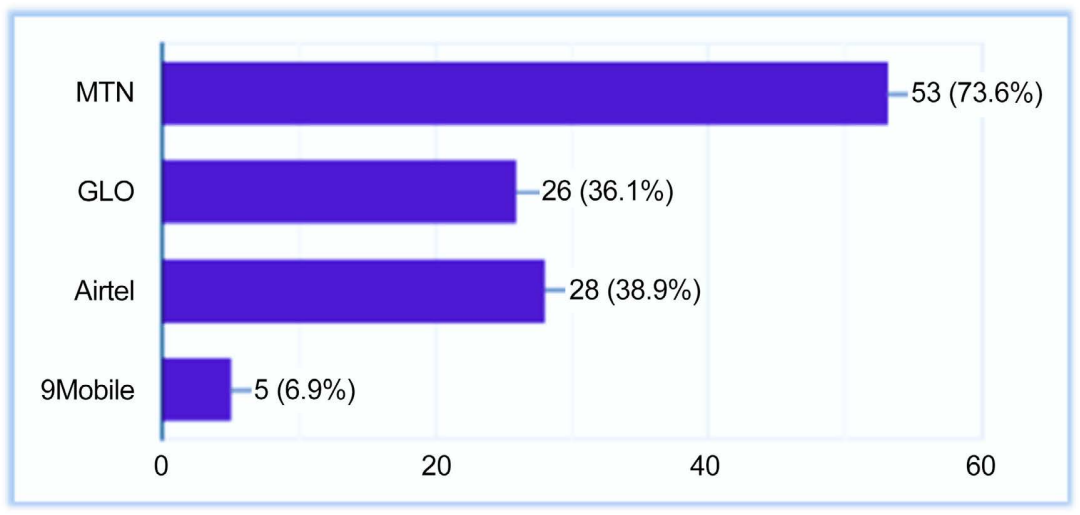

Figure 4. Network service providers with their number of their customers.

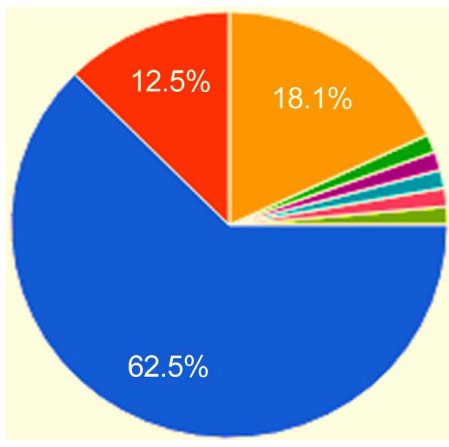

Figure 5. The figure illustrating the distribution of subscribers experiences with their various network providers.

providers but are helpless on what to do. This is because they have used these phone numbers for various registrations. In Nigeria, common to change phone number for bank alerts take a whole lot of bureaucratic processes; hence the fear. To save customers from this, the protesters should be supported with a technology that will help them to generate enough force that will cause their network service providers to reverse their obnoxious services or at least appeal to the protesters.

Secondly, greater numbers of protest users found within our respondents disclosed the kind of tactics they employ in carrying out their protests. This action in itself as noted by [30] introduces promising opportunity for computer-aided collective action. For instance, a smart technology could be developed to identify and mobilize protest users across each of the mobile network providers. The protesters could use this technology to schedule their action plans to enable them achieve their aim of the protest. The action plan could be to inform the protesters the kind of services they can subscribe and the once they can boycott. Some people could even continue to borrow data subscriptions from the network without repaying, depending on the tactics the protesters chose to adopt.

\subsection{System Design with Users in Mind}

In technology design, everyone matters; the high-end users and all other stake- 
holders must be considered, knowing that users' peculiarities abounds. So, keeping the users in mind during the system design will take care of several headaches after system deployment. It helps designer to project himself into the shoes of the various users-professional, expert, novice, etc. and be able to accommodate them in the technology to avoid much negative feedbacks and perception. This is an approach that would further supplement existing user-centered design approaches, such as participatory design and value-sensitive design [31] [32] [33].

\subsection{Gender-Based Classification of Protest Users among the Network Subscribers}

This study exposed the sub-domain of technology non/use and the kind of behaviours exhibited by protest users in response to [9] called for examining "relationship between different forms of technology non-use and different types of motivations" [9]. We tried to understand the peculiarities that exist among the protesting subscribers-male or female. From our respondents, we found out that the rate of male to female respondents is $85 \%$ - $15 \%$ while the rate of protesters among the network subscribers is $82 \%$. From the above data, it would be instructive to say that male protesters are more than the female considering the size of our respondents. We may not be able to substantiate the reason behind this finding but that will be left for further research.

\subsection{Protest Users versus Company Monopolies}

One of the observations we made in our survey is that many subscribers felt they could not change their network service providers even though there is an alternative service providers because of their level of commitment with their present network service providers. Many claimed that they have used their mobile numbers in so many sensitive and official registrations and couldn't afford to lose their numbers. This finding provides a data point for the growing discussions about monopoly power of many of the companies in the technology industry [32] [34] [35] [36]. Some of these subscribers according to our survey decided to stick with their network provide because they have tried others and they could not experience any better service.

\subsection{Function of Our Proposed System}

Our proposed technology code-named "Komplain" is designed to serve as a complainant recruitment platform that will help to bring together mobile network subscribers in Ebonyi state with similar mobile network challenges to enable them embark on collective consumers/subscribers actions. The system also contains some suggestive actions that the aggrieved subscribers could engage themselves in order to press home their demands. These action could be consumer data strike, negative service scoring, call service airtime boycott, data subscription boycott, petition to public complaint commission (PCC), petition to con- 
sumer protection commission (CPC), petition to Nigeria communication commission (NCC), collection of public signatures to sign petition, online poll to score telecom companies based on their quality of service to the network subscribers in the state, etc.

The platform is open source that allows users to customize the appearances of their walls. But the system provides limited access for typing inputs from the users. It offers high priority to selection and clickable input responses from the users. The limitation of users' keyboard inputs is to control the kinds of feedbacks they provide. This will also help to minimize user errors and negative/out of context responses. Complaints are posted to the general platform after double blind verification by the system administrator in order to ascertain the authenticity of every post. This is to ensure the integrity of the system is maintained.

The telecom company being protested against has a window provided for them where they can file their defense and as well make further clarifications where necessary. The system provides for open and anonymous complain but the person must register with the system first before making any public complain. The results of each complain is analyzed using data representation tools such as pie chart and bar chart.

\subsection{Limitation of the Study}

Our study duration is short and this contributed to the number of people that participated in our collection. We could only cover Ebonyi state, one of the thirty-six states of Nigeria. We used Ebonyi state as our case study owing to the grow complaints coming from the subscribers resident in the state. These complaints actually motivated our research to consider mainly the negative experiences of the subscribers with their networks service providers. A further study will be needed to assess the positive impacts of the network services providers on their subscribers.

\section{Conclusions}

This paper aimed at obtaining the users experiences of mobile network service subscribers in Ebonyi State, Nigeria. In this light, we accessed the users' actions and the activities that triggered them into performing such action which we labeled users protest. The results of our survey here presented explored why the subscribers change their network service providers and their reasons. Our result showed that such behavior is increasingly common among the network subscribers. These subscribers are spurred into this action by varying factors, such as poor services, high tariffs on call and data service, high network down-time, etc.

In order to ameliorate the problem already found, a design prototype that would help protesters to collectively channel their complaints against any tech companies was proposed. This platform will enable recruitment of people with similar demands and complains. We suggest that these network service provid- 
ers should incorporate this technology into their service platforms. This platform would also serve as a persuasive platform for both parties [37].

\section{Acknowledgements}

We are grateful to our respondents and the authors whose works we consulted. This research did not receive any funding from neither government nor corporate organization.

\section{Conflicts of Interest}

The authors declare no conflicts of interest regarding the publication of this paper.

\section{References}

[1] Granville, K. (2018, March) Facebook and Cambridge Analytica: What You Need to Know as Fallout Widens.

[2] Greenfield, R., Frier, S. and Brody, B. (2018, December) NAACP Seeks Week-Long Facebook Boycott Over Racial Targeting.

[3] Semuels, A. (2017, February) Why \#DeleteUber and Other Boycotts Matter.

[4] Kasperkevic, J. (2018, December) Amazon Faces Boycott Ahead of Holidays as Public Discontent Grows.

[5] Li, H., Alarcon, B., Espinosa, S.M. and Hecht, B. (2018) Out of Site: Empowering a New Approach to Online Boycotts. Proceedings of the ACM on Human-Computer Interaction, 2, Article No. 106. https://doi.org/10.1145/3274375

[6] Nathan Matias, J. (2016) Going Dark: Social Factors in Collective Action Against Platform Operators in the Reddit Blackout. Proceedings of the 2016 CHI Conference on Human Factors in Computing Systems (CHP 16), San Jose, 7-12 May 2016, 1138-1151. https://doi.org/10.1145/2858036.2858391

[7] Posner, E.A. and Glen Weyl, E. (2018) Radical Markets. Uprooting Capitalism and Democracy for a Just Society. Princeton University Press, Princeton. https://doi.org/10.23943/9781400889457

[8] Vincent, N., Hecht, B. and Sen, S. (2019) "Data Strikes": Evaluating the Effectiveness of New Forms of Collective Action Against Technology Platforms. Proceedings of the Web Conference 2019, San Francisco, 13-17 May 2019, 1931-1943. https://doi.org/10.1145/3308558.3313742

[9] Baumer, E.P.S. (2018) Socioeconomic Inequalities in the Non Use of Facebook. Proceedings of the 2018 CHI Conference on Human Factors in Computing Systems (CHP 18), Montreal, 21-26 April 2018, Article No. 616. https://doi.org/10.1145/3173574.3174190

[10] Baumer, E.P.S., Ames, M.G., Burrell, J., Brubaker, J.R. and Dourish, P. (2015) Why Study Technology Nonuse? First Monday, 20, No. 10. https://doi.org/10.5210/fm.v20i11.6310

[11] Satchell, C. and Dourish, P. (2009) Beyond the User: Use and Non-Use in HCI. Proceedings of the 21 st Annual Conference of the Australian Computer-Human Interaction Special Interest Group: Design: Open 24/7, Melbourne, 23-27 November 2009, 9-16. https://doi.org/10.1145/1738826.1738829

[12] Wyatt, S.M.E., Oudshoorn, N. and Pinch, T. (2003) Non-Users Also Matter: The 
Construction of Users and Nonusers of the Internet. In: Oudshoorn, N. and Pinch, T., Eds., How Users Matter: The Co-Construction of Users and Technology, The MIT Press, Cambridge, 67-79. https://doi.org/10.7551/mitpress/3592.003.0006

[13] Opata, C. (2013) The Curious Consumer Dissatisfaction in Nigeria Telecommunications Sector. Faculty of Law, University of Nigeria, Enugu.

https://doi.org/10.2139/ssrn.2356804

[14] Baumer, E.P.S., Adams, P., Khovanskaya, V.D., Liao, T.C., Smith, M.E., Sosik, V.S. and Williams, K. (2013) Limiting, Leaving, and (Re)Lapsing: An Exploration of Facebook Non-Use Practices and Experiences. Proceedings of the SIGCHI Conference on Human Factors in Computing Systems (CHI'13), Paris, 27 April-2 May 2013, 3257-3266. https://doi.org/10.1145/2470654.2466446

[15] Hargittai, E. (2007) Whose Space? Differences among Users and Non-Users of Social Network Sites. Journal of Computer-Mediated Communication, 13, 276-297. https://doi.org/10.1111/j.1083-6101.2007.00396.x

[16] Schoenebeck, S.Y. (2014) Giving Up Twitter for Lent: How and Why We Take Breaks from Social Media. Proceedings of the SIGCHI Conference on Human Factors in Computing Systems (CHI'14), Toronto, 26 April-1 May2014, 773-782. https://doi.org/10.1145/2556288.2556983

[17] Baumer, E.P.S. (2015) Usees. Proceedings of the 33rd Annual ACM Conference on Human Factors in Computing Systems (CHI'15), Seoul, 18-23 April 2015, 3295-3298. https://doi.org/10.1145/2702123.2702147

[18] Baumer, E.P.S., Burrell, J., Ames, M.G., Brubaker, J.R. and Dourish, P. (2015) On the Importance and Implications of Studying Technology Non-Use. Interactions, 22, 52-56. https://doi.org/10.1145/2723667

[19] Baumer, E.P.S., Guha, S., Quan, E., Mimno, D. and Gay, G.K. (2015) Missing Photos, Suffering Withdrawal, or Finding Freedom? How Experiences of Social Media Non-Use Influence the Likelihood of Reversion. Social Media + Society, 1, Article ID: 2056305115614851. https://doi.org/10.1177/2056305115614851

[20] King, B. (2016). Reputation, Risk, and Anti-Corporate Activism: How Social Movements Influence Corporate Outcomes. In: Bosi, L., Giugni, M. and Uba, K., Eds., The Consequences of Social Movements, Cambridge University Press, Cambridge, 215-236. https://doi.org/10.1017/CBO9781316337790.009

[21] King, B.G. and McDonnell, M.H. (2015) Good Firms, Good Targets: The Relationship among Corporate Social Responsibility, Reputation, and Activist Targeting. In: Tsutsui, K. and Lim, A., Eds., Corporate Social Responsibility in a Globalizing World, Cambridge University Press, Cambridge, 430-454.

https://doi.org/10.1017/CBO9781316162354.013

[22] McDonnell, M.-H., King, B.G. and Soule, S.A. (2015) A Dynamic Process Model of Private Politics: Activist Targeting and Corporate Receptivity to Social Challenges. American Sociological Review, 80, 654-678. https://doi.org/10.1177/0003122415581335

[23] Newman, B.J. and Bartels, B.L. (2011). Politics at the Checkout Line: Explaining Political Consumerism in the United States. Political Research Quarterly, 64, 803-817. https://doi.org/10.1177/1065912910379232

[24] Koos, S. (2012) What Drives Political Consumption in Europe? A Multi-Level Analysis on Individual Characteristics, Opportunity Structures and Globalization. Acta Sociologica, 55, 37-57. https://doi.org/10.1177/0001699311431594

[25] Lotz, A. (2019) “Big Tech" Isn't One Big Monopoly-It's 5 Companies All in Different Businesses. 
[26] Buycott (2018) Buycott App. https://www.buycott.com/

[27] Guha, S., Baumer, E.P.S. and Gay, G.K. (2018) Regrets, I've Had a Few: When Regretful Experiences Do (and Don't) Compel Users to Leave Facebook. Proceedings of the 2018 ACM Conference on Supporting Groupwork (GROUP '18), Sanibel Island, 7-10 January 2018, 166-177. https://doi.org/10.1145/3148330.3148338

[28] Nweso, E.N. and Ogbaga, I.N. (2016) Internet Access via Cable Television Network as Better Alternative for Home Network Deployment. EPRA International Journal of Multidisciplinary Research (IJMR), 2, 1-7.

[29] Overdorf, R., Kulynych, B., Balsa, E., Troncoso, C. and Gürses, S. (2018) POTs: Protective Optimization Technologies. arXiv preprint arXiv:1806.02711.

[30] Shaw, A., Zhang, H., Monroy-Hernández, A., Munson, S., Hill, B.M., Gerber, E., Kinnaird, P. and Minder, P. (2014) Computer Supported Collective Action. Interactions, 21, 74-77. https://doi.org/10.1145/2576875

[31] Friedman, B. and Nissenbaum, H. (1996) Bias in Computer Systems. ACM Transactions on Information Systems, 14, 330-347.

https://doi.org/10.1145/230538.230561

[32] Herndon, A.W. (2019) Elizabeth Warren Proposes Breaking Up Tech Giants Like Amazon and Facebook.

[33] Muller, M.J. (2003) The Human-Computer Interaction Handbook. Jacko, J.A. and Sears, A., Eds., L. Erlbaum Associates Inc., Hillsdale, 1051-1068.

[34] Manjoo, F. (2018) Stumbles? What Stumbles? Big Tech Is as Strong as Ever.

[35] Martínez, A.G. (2019) Facebook Is Not a Monopoly, but It Should Be Broken Up.

[36] Wright, R. (2018) Why We Can't Let Google Monopolize AI.

[37] Nkwo, M.S., Orji, R., Ajah, I., Igwe, J., Ogbaga, I. and Chigozie-Okwum, C. (2021) Design Opportunities for Persuasive Mobile Apps to Support Maternal and Child Healthcare and Help-Seeking Behaviors. 3rd African Human-Computer Interaction Conference (AfriCHI 2021), Maputo, 8-12 March 2021, 33-42.

https://doi.org/10.1145/3448696.3448707 